\title{
Path taken in a Fontan circulation: room for optimism in the face of uncertainty
}

\author{
Jack Rychik
}

Survival into adulthood for individuals born with single ventricle congenital heart disease is now possible. In the 1970s and 1980s, early efforts emphasised the exploration of optimal techniques and strategies necessary to create survival. How best to palliate in infancy and bring an individual child with single ventricle to the point of good candidacy to survive through Fontan operation was the goal. Today, refinements in the strategy of early care are still necessary, as many patients continue to struggle to get to-and sometimes through-the Fontan operation stage. However, there is also a new reality and a new perspective. Reaping the rewards of surgical success of the past five decades, we now have the capacity to not just look at individual patients or case series results, but to observe and analyse populationbased outcomes in adults with a Fontan circulation.

What is clear to anyone caring for patients with single ventricle and Fontan circulation is that no two individuals are exactly alike. There is tremendous heterogeneity in the make-up of the substrate, as well as huge variability in outcomes and quality of life. Dozens of forms of congenital heart defects can manifest as an inadequate two-ventricle system and thus require a Fontan circulation. Each variant brings its own unique genotype and specific phenotype, risks and perils, to the table. The entire course of care starting from prenatal management through Fontan surgery is an eventful and arduous one, with potential for myriad of impactful events, each of which lays the groundwork for processes that influence later outcomes in life.

What all patients with single ventricle and Fontan circulation share are the physiological stressors of elevated central venous pressure, relatively low cardiac output and a host of unique consequences affecting end-organ functional status. ${ }^{1}$ It is reasonable to look at the population as a whole based on the commonality of Fontan circulatory physiology, but how

Division of Cardiology, Children's Hospital of Philadelphia, Philadelphia, Pennsylvania, USA

Correspondence to Dr Jack Rychik, Children's Hospital of Philadelphia, Philadelphia, PA 19104, USA; rychik@email.chop.edu best to begin to understand the tremendous variability in outcomes? Baker and colleagues in this issue of Heart ${ }^{2}$ engage this question by using the database of the Australia New Zealand Fontan Registry (ANZFR) and provide a population-based approach. By analysing patients who survived to $\geq 16$ years of age, these investigators stratified a population of over 800 subjects on the basis of risk factors into 'low' or 'increased' risk for late outcomes including transplant-free survival. Risk factors included sustained arrhythmia requiring treatment, Fontan conversion surgery, thromboembolic event, lymphatic insufficiency manifestations such as protein losing enteropathy or plastic bronchitis, New York Heart Association functional class III or IV and moderate or worse ventricular dysfunction or atrioventricular valve regurgitation. Nearly threequarters of the cohort were low risk-not owning a single one of these risk factors. Freedom from death or transplantation for low risk versus high risk was $94 \%$ vs $82 \%$ at 30 years and $85 \%$ vs $76 \%$ at 40 years, respectively.

What does this study teach us? Importantly, an opportunity for optimism. First, we now have data to support the concept that a substantial number of patients with Fontan circulation will survive far into adulthood. This debunks a long-standing myth that the circulation will ultimately 'time-out' and that all patients with single ventricle will ultimately require heart transplantation. On the contrary, databased projection modelling suggests we will be seeing a substantial number of lowrisk individuals reach their sixth decade of life-remarkable! Next, the emergence from adolescence into adulthood in a relatively well state is crucially important. An 'unnatural' selection process may be at play in early life, with those transitioning into young adulthood in a well state, as the best of cases. The curve defining prevalence for some of the life-threatening risks may not necessarily be linearly progressive with age. Liver fibrosis as a complication may be an exception as this does appear to progress with age $^{3}$; however, it is not yet a factor contributing significantly to survival. Nevertheless, a model to consider is that in the lifespan journey of the individual with single ventricle heart disease, some of the challenges and hurdles along the path may tend to occur early in the first two decades of life. For all of us, life is a journey defined by a long and winding road. For those with single ventricle, if one emerges from the roadway curve of adolescence in a relatively good state, then the path is far from risk free, but perhaps less treacherous than in the earliest of years.

How do we get more patients to enter adulthood in a well, risk-free state such that their best potential for longterm survival into late adulthood can be achieved? There are a number of things to consider. The Barker hypothesis describes 'fetal programming' in which early prenatal variables influence later adult-onset cardiovascular disease. ${ }^{4}$ Using this conceptual model, there are likely prenatal and early childhood factors that influence and 'program' later adult outcomes in a Fontan circulation. Creating a lifespan database registry that includes variables from prenatal through adult life will allow us to identify factors associated with wellness that might be enhanced and amplified, or complications that may be modified and averted. ${ }^{5}$ The genetic basis of risk-related variables needs to be ascertained. The ANZFR proves the incredible power of a database, with only a modest degree of clinical characterisation. Imagine the depths of knowledge and understanding gained if a lifespan registry were to exist, linked to a biorepository of genetic material. Early lifestyle habits including nutritional factors may be crucially important. For example, obesity and vitamin D insufficiency-potentially modifiable variables-have been shown negatively associated with functional exercise. ${ }^{6}$ Muscle mass and exercise in general are emerging as important contributors to overall wellness. ${ }^{7}$ Initiating individualised exercise training regimens early may prove to be a valuable contributor to future mental as well as cardiovascular health. Importantly, development of tools such as a Fontan circulationspecific 'wellness score' compiled from surveillance testing data and applied in the clinic to accurately assess and grade comprehensive clinical status would allow for early identification of at-risk individuals and implementation of therapies to stave off or delay complications.

After first traversing numerous bends in the road, a path with an optimistic future is possible for those with a Fontan circulation. Let's get to work on making sure we can direct as many as possible onto that path. 
Contributors JR is the sole author of this article.

Funding The authors have not declared a specific grant for this research from any funding agency in the public, commercial or not-for-profit sectors.

\section{Competing interests None declared.}

Patient and public involvement Patients and/ or the public were not involved in the design, or conduct, or reporting, or dissemination plans of this research.

Patient consent for publication Not required.



\section{OPEN ACCESS}

Open access This is an open access article distributed in accordance with the Creative Commons Attribution Non Commercial (CC BY-NC 4.0) license, which permits others to distribute, remix, adapt, build upon this work non-commercially, and license their derivative works on different terms, provided the original work is properly cited, appropriate credit is given, any changes made indicated, and the use is non-commercial. See: http://creativecommons.org/ licenses/by-nc/4.0/.

(c) Author(s) (or their employer(s)) 2021. Re-use permitted under CC BY-NC. No commercial re-use. See rights and permissions. Published by BMJ.

\section{Check for updates}

To cite Rychik J. Heart 2021;107:521-522.

Published Online First 23 December 2020

\section{CLinked}

- http://dx.doi.org/10.1136/heartjnl-2020-317619

Heart 2021;107:521-522.

doi:10.1136/heartjnl-2020-318348

\section{ORCID iD}

Jack Rychik http://orcid.org/0000-0001-8625-6565

\section{REFERENCES}

1 Rychik J, Atz AM, Celermajer DS, et al. American heart association Council on cardiovascular disease in the young and Council on cardiovascular and stroke nursing. evaluation and management of the child and adult with Fontan circulation: a scientific statement from the American heart association. Circulation 2019;1:CIR0000000000000696.

2 Baker DW, Dennis MR, Zannino D. Path ahead for 'low risk' adolescents living with a Fontan circulation. Heart 2021;107:556-62.

3 Goldberg DJ, Surrey LF, Glatz AC, et al. Hepatic fibrosis is universal following Fontan operation, and severity is associated with time from surgery: a liver biopsy and hemodynamic study. J Am Heart Assoc 2017:6:e04809.

4 Barker DJ, Winter PD, Osmond C, et al. Weight in infancy and death from ischaemic heart disease. Lancet 1989;2:577-80.

5 Alsaied T, Allen KY, Anderson JB, et al. The Fontan outcomes network: first steps towards building a lifespan Registry for individuals with Fontan circulation in the United States. Cardiol Young 2020;30:1070-5.

6 Weinreb SJ, Dodds KM, Burstein DS, et al. End-Organ function and exercise performance in patients with Fontan circulation: what characterizes the high performers? J Am Heart Assoc;2020.

7 Tran D, D'Ambrosio P, Verrall CE, et al. Body composition in young adults living with a Fontan circulation: the Myopenic profile. J Am Heart Assoc 2020;9:e015639. 